\title{
Thank you Jan van Gijn
}

\author{
Roger Barker $\cdot$ Massimo Filippi $\cdot$ Michael Strupp
}

Published online: 23 May 2013

(C) Springer-Verlag Berlin Heidelberg 2013

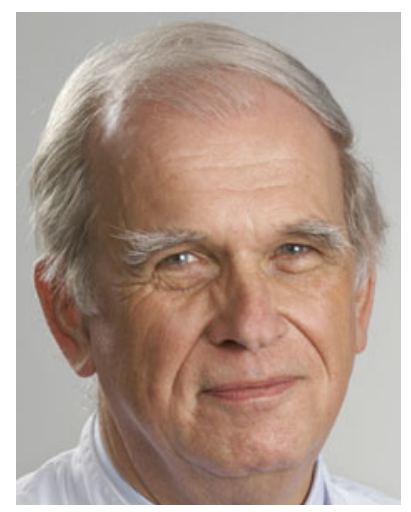

It is with much regret on our part that we announce that Jan van Gijn has decided to stand down as the pioneering spirit and lead of our "Pioneers of Neurology" section, a role he took on after his time as Joint Chief Editor came to an end in 2000. Over this time, he has solicited many fabulous articles to which he has often added his own edits to craft

R. Barker $(\bowtie)$

Cambridge Centre for Brain Repair, University of Cambridge,

The E.D. Adrian Building, Forvie Site, Robinson Way,

Cambridge CB2 2PY, UK

e-mail: rab46@cam.ac.uk

\section{Filippi}

Neuroimaging Research Unit, Institute of Experimental Neurology, Division of Neuroscience, San Raffaele Scientific Institute and Vita-Salute San Raffaele University,

Via Olgettina 60, 20132 Milan, Italy

e-mail: filippi.massimo@hsr.it

\section{Strupp}

Department of Neurology, University Hospital Munich, Campus Grosshadern, Marchioninistrasse 15, 81377 Munich, Germany e-mail: Michael.Strupp@med.uni-muenchen.de

the accounts into what has become a unique and much loved part of the Journal of Neurology.

Jan qualified from the Erasmus University in Rotterdam in the late 1970s and subsequently worked in the Neurology department in Rotterdam until he became head of the University Department of Neurology in Utrecht in 1991. He worked tirelessly there developing his own research in the clinical science of cerebrovascular disease. He has been in receipt of many awards, is a member of many illustrious international societies and has been a leading figure in many of the defining studies in stroke. He has written extensively in this area of research and has served on the editorial board, or as associate editor, of many prestigious neurological journals.

Jan became Co-Editor in Chief of the Journal of Neurology in 1993, first with Alastair Compston and then with David Miller before handing on the baton to Thomas Brandt. It was at this point that he took on the challenge of this new section and which he now wishes to pursue further in his retirement through work in the history of neurology. At the moment, though, he is back to school as a full time student of Latin at the University of Amsterdam. It is, therefore, a great loss for us as Jan leaves his editorial role within the Journal of Neurology 20 years after it began, but we wish him all the very best for the future and hope that he does well in his new exams! We are though pleased to say that Andrew Larner has agreed to take on the running of the Pioneers of Neurology section. 